\title{
Comparison of standard mammography with digital mammography and digital infrared thermal imaging for breast cancer screening
}

\author{
Meme kanseri taramasında standart mamografi ile dijital mamografi ve dijital \\ infrared termal görüntülemenin karşılaştrılması
}

\author{
Nermin Köşüş, Aydın Köşüş, Müzeyyen Duran, Serap Simavı, Nilgün Turhan \\ Department of Obstetrics and Gynecology, Faculty of Medicine, Fatih University, Ankara, Turkey
}

\section{Abstract}

Breast cancer is the most common malignancy in women. Screenfilm mammography (SFM) has been considered the gold standard for breast cancer screening and detection. Despite its recognized value in detecting and characterizing breast disease, mammography has important limitations and its false-negative rate ranges from $4 \%$ to $34 \%$. Given these limitations, development of imaging modalities that would enhance, complement, or replace mammography has been a priority. Digital mammography (FFDM) and digital infrared thermal imaging (DITI) are some of these alternative modalities.

(J Turkish-German Gynecol Assoc 2010; 11: 152-7)

Key words: Mammography, digital mammography, digital infrared thermal imaging, breast cancer

Received: 9J une, 2010

Accepted: 6 August, 2010

\section{Introduction}

Breast cancer is the most common malignancy and the second most common cause of cancer death in women in the US (1). According to the American Cancer Society report on cancer facts, it accounts for about $30 \%$ of all cancers in women. Approximately one in every eight women is diagnosed with breast cancer by the age of 90 , with an absolute lifetime risk of $14.4 \%$ (2).

In Turkey, the ratio of breast cancer is $24.1 \%$, ranking first of all the cancers in women (3). The incidence of breast cancer has increased, and the estimated number of breast cancer cases was 44,253 in $2007(4,5)$. There is a geographical heterogeneity regarding breast cancer incidence and survival rates in Turkey. The incidence in Western Turkey (50/100,000 in 2000) is more than twice that of the Eastern part $(20 / 100,000)(5-7)$. Five year survival rates for breast cancer are $85 \%$ in Western and $60 \%$ in Eastern Turkey (7).

Breast cancer survival depends upon its earliest possible detection because survival rate increases with earlier detection with a possibility of complete cure. Breast cancer has a ten year survival rate for Stage 0of 95\%; Stage I, 88\%; Stage II,

\section{Özet}

Meme kanseri kadınlarda görülen en yaygın malignitedir. Mamografi hem tarama hem de saptama bakımından altun standarttr. meme kanserindeki bu değerine rağmen mamografide önemli kısıtlamalar mevcuttur ve yanlış negatiflik oranı \%4-34 arasında değişmektedir. Bu kısıtlamalar nedeniyle görüntüleme yönteminin geliștirmek elzem olmuştur. Dijital mamografi ve dijital infrared termal görüntüleme diğer bazı alternatif yöntemlerdir.

(J Turkish-German Gynecol Assoc 2010; 11: 152-7)

Anahtar kelimeler: Mamografi, dijital mamografi, dijital infrared termal görüntüleme, meme kanseri

Geliş Tarihi: 09 Haziran 2010

Kabul Tarihi: 06 Ağustos 2010

66\%; Stage III, 36\%; and stage IV, 7\% (8). Larger tumor size at diagnosis is also associated with decreased survival (9).

Screening might produce greater benefits for early detection if it were more sensitive and specific. A wide variety of new technologies, including alternative imaging modalities, and improvements in x-ray mammography, are being investigated with the aim of improving early-detection rates.

Many imaging modalities can be used for breast screening, such as X-ray; ultrasonography, magnetic resonance imaging (MRI); computed tomography (CT); ultrasound; positron emission tomography (PET) scans, digital mammography (FFDM) and lastly digital infrared thermal imaging (DITI) which is currently increasing in popularity.

This review of the scientific literature aims to assess the safety and efficacy of screen-film mammography (SFM) and ultrasonography compared to FFDM and DITI for the detection of breast cancer.

\section{Mammography}

SFM has been considered the gold standard for breast cancer screening and detection (1). It has been used currently as the most effective method of detecting asymptomatic breast 
cancer. Its use for screening has been widely promoted by the National Cancer Institute and other organizations (1, 3). Over $70 \%$ of women in the US over the age of 40 have had a mammogram within the past 2 years (8).

A prior research has investigated the efficacy of SFM at reducing mortality from breast cancer (9). Meta-analyses of randomizedcontrol trials of mammography screening show a 25-30\% reduction in breast cancer mortality for women over 50 , and a smaller, more equivocal effect in women aged 40-49. Most experts agree that mammography screening is beneficial for women between 50-69 years old (10).

Despite its recognized value in detecting and characterizing breast disease, mammography has important limitations: first, its false-negative rate ranges from $4 \%$ to $34 \%$, depending on the definition of a false negative and on the length of followup after a "normal" mammogram. Second, screening mammography is less sensitive in women with radiographically dense breast tissue. This is of particular concern because the amount of fibroglandular tissue may represent an independent risk factor for developing breast cancer. Thirdly, screening mammography also suffers from a high false-positive rate: on average, 75\% of breast biopsies prompted by a "suspicious" mammographic abnormality have proved to be benign (3). The other drawbacks include discomfort due to breast compression, variability in radiological interpretation, and a slight risk of inducing cancer due to the ionizing radiation exposure (11). Another important point is over treatment which was explained in a new study by Gotzsche reporting that screening actually leads to more aggressive treatment, increasing the number of mastectomies by about $20 \%$ and the number of mastectomies and tumorectomies by about 30\% (12-14).

Given these deficits, development of new imaging modalities or techniques that would enhance, complement, or replace mammography has been a priority (15). Current alternatives to screen-film mammography have included full-field digital mammography and digital infrared thermal imaging.

\section{Digital mammography}

High-quality full-field digital mammography (FFDM) addresses some of the limitations seen with SFM and is increasingly used for both diagnostic and screening mammography (16).

In women with an nonhomogeneous or extremely dense parenchymal breast pattern, the detection of breast cancer is difficult due to the similar X-ray absorption of carcinoma to the surrounding normal dense breast tissue (17). Digital mammography is superior to screen-film mammography in younger women with dense breasts due to its ability to selectively optimize contrast in areas of dense parenchyma (18). This advantage is especially important in women with a genetic predisposition for breast cancer, where intensified early detection programs may need to start from 25 to 30 years of age.

As screening programs involve large populations of healthy patients, digital mammography should offer considerable benefits in terms of radiation dose, image quality, data transfer and data archiving $(16,18)$. Two different technologies have been developed in digital mammography (17). Off-line systems with a cassette-based removable detector use an external reading device to generate the digital image; whereas in on-line systems, the detector is integrated into the digital mammography unit and the digital image data are directly read by the system in quasi real time.

Full-field digital mammography (Figure 1) allows direct image analysis from high-resolution monitors. High-resolution digital monitors allow the reader to adjust image contrast, magnification, and use other image-processing algorithms that might improve the accuracy of interpretation. As the technology matures and radiologists gain experience, the accuracy of digital mammography for diagnostic imaging is likely to improve. The full-field digital mammography system used delivers an average of $27 \%$ dose less than screen film mammography (19). Such dose-gain changes with breast thickness, from about $15 \%$ for thin $(30-40 \mathrm{~mm})$ and thick $(<70 \mathrm{~mm})$ breasts up to $30-40 \%$ for more typical intermediate thickness values (19). Dose equivalence for very thin breasts below $30 \mathrm{~mm}$ was found.

The interpretation of mammograms, regardless of the technology used, remains a difficult art. A large percentage of breast cancers are missed, and false-positive mammograms are also a substantial problem. Furthermore, the long-term benefits from mammography screening, especially in women under the age of 50, are relatively small and continue to be debated, partly because of the lower incidence of breast cancer among younger women and the lower sensitivity of mammography in this group due to the density of their breast tissue (17).

The American College of Radiology Imaging Network (ACRIN) collected screening mammography studies performed by using both digital and screen-film mammography in 49,528 women

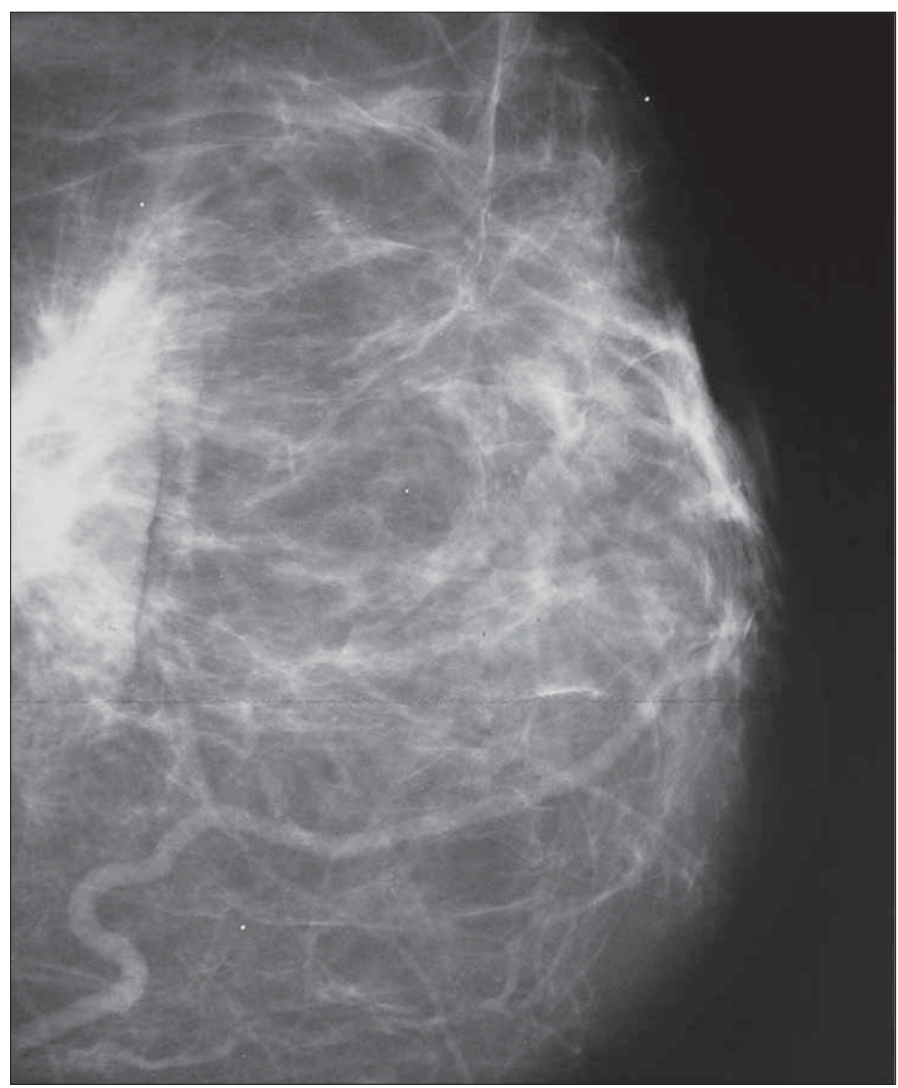

Figure 1. Image of digital mammography 
(mean age, 54.6 years; range, 19-92 years) for a huge Digital Mammographic Imaging Screening Trial (DMIST). The study has confirmed that diagnostic accuracy with digital mammography is significantly better than that with screen/film for subgroups of patients, such as young women, women with dense breasts, and pre-menopausal women (20). The improved sensitivity of FFDM in this group is expected to lead to improvements in longterm outcomes. However, randomized clinical trials of women between the ages of 40 and 49 years have suggested that only equivocal mortality benefits are obtained with screening mammography. The delicate balance of risks and benefits can be affected by small differences in the accuracy of both the mammographic technology and image interpretation. Thus, it will be increasingly important to carefully evaluate the characteristics of any technology that may replace SFM.

Digital full-field mammography could become the method of choice in the detection and characterization of breast cancer. The limitation of digital mammography is the initial cost of the system and the discrepancy between this cost and the current rate of reimbursement. Other aspects like limited detector size or the lack of an automatic exposure control of some systems should be solved in time.

Overall, the evidence to date does not support the use of FFDM for screening or detection of breast cancer in all women. Although the DMIST demonstrated equivalence of the two technologies, FFDM is significantly more expensive. FFDM does have the potential to achieve better sensitivity and specificity than SFM in some subgroups of women (19). If FFDM would improve sensitivity slightly while sacrificing specificity, the overall harm from increased false positive results and increased biopsies would likely outweigh the increased detection rate, as the vast majority of women undergoing screening mammography do not have breast cancer.

\section{B reast ultrasonography}

Breast ultrasonography (Figure 2) is a relatively inexpensive and effective method of differentiating breast masses. Cysts and solid lesions are difficult to differentiate on mammography alone, and ultrasound is especially important in this situation since it can differentiate cystic or solid tumor. USG is also superior to mammography in the evaluation of breast abscesses (21-23). On the other hand, small calcifications are not easily seen on screening with ultrasound only, so mammography combined with breast ultrasonography are the standard imaging techniques for detection and evaluation of breast disease (24) in individuals over 30 years with a small palpable lump.

USG does not expose a patient to ionizing radiation, which is particularly important for pregnant patients and young patients. With the help of Doppler ultrasonography, detection of the presence and degree of vascularity of breast masses become easier and enables correct identification and treatment of masses. US is also useful in the guidance of biopsies and therapeutic procedures.

The choice of primary breast imaging in examining women with symptoms is partly based on age. It was shown by many studies that there is a progressive improvement in sensitivity of mammography in women 60 years or older relative to younger women (25). However, in women 45 years or younger, ultrasound has a significantly greater sensitivity than mammography.

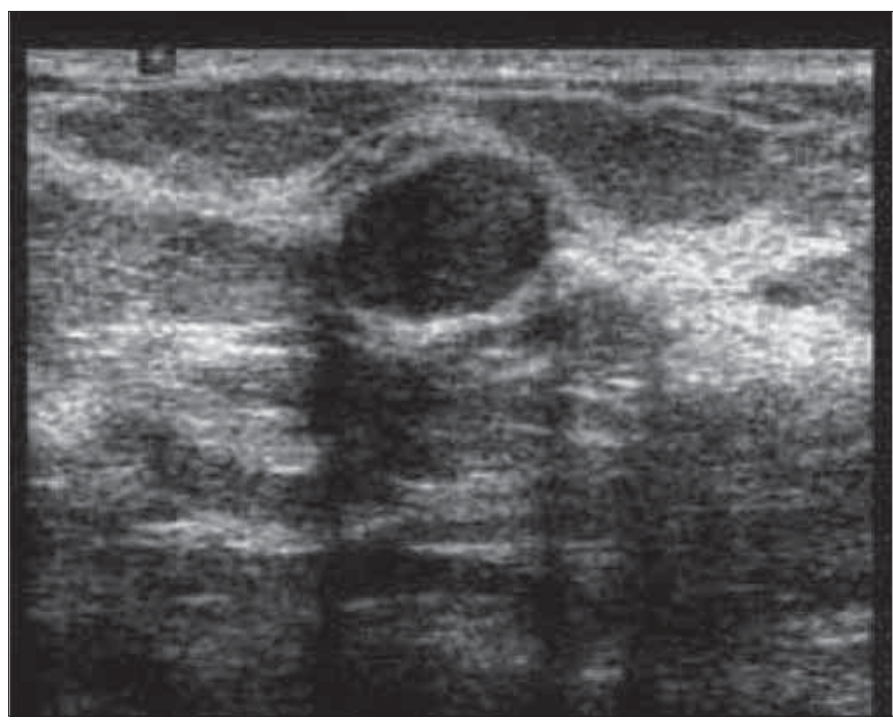

Figure 2. Image of breast ultrasonography

US is useful in the evaluation of palpable masses that are mammographically occult, in the evaluation of clinically suspected breast lesions in women younger than 30 years of age, and in the evaluation of many abnormalities seen on mammograms. Dense fibroglandular tissue is the most important inherent limitation of mammography in the diagnosis of breast cancer. USG is more sensitive than mammography in detecting lesions in women with dense breast tissue $(24,25)$.

In the study of Berg et al. 2809 women, with at least heterogeneously dense breast tissue in at least 1 quadrant, were recruited to undergo mammographic and physician-performed ultrasonographic examinations. Forty participants (41 breasts) were diagnosed with cancer: 8 suspicious on both ultrasound and mammography, 12 on ultrasound alone, 12 on mammography alone, and 8 participants ( 9 breasts) on neither. The diagnostic yield for mammography was 7.6 per 1000 women screened ( 20 of 2637) and increased to 11.8 per 1000 (31 of 2637) with combined mammography plus ultrasound. The diagnostic accuracy for mammography was 0.78 and increased to 0.91 for mammography plus ultrasound (ACRIN).

Although some researchers have reported reasonable results from US breast screening, a number of serious issues such as interobserver and intraobserver variability, need to be solved before the practice is recommended for general application. Thus experts suggest that women younger than 35 years be examined with ultrasound, and women 35 years and older be examined with mammography, as the primary breast imaging modality (21).

\section{Digital infrared thermal imaging (Diti)}

Thermography is a technique for measuring the body surface temperature and is used in medical applications. Infrared imaging is a physiological test that measures the subtle physiological changes that might be caused by many conditions, such as contusions, fractures, burns, carcinomas, dermatological diseases, rheumatoid arthritis, diabetes mellitus and associated pathology, deep venous thrombosis, liver disease, bacterial infections, and others $(25,26)$. 
These conditions are commonly associated with regional vasodilation, hyperthermia, hyperperfusion, hypermetabolism, and hypervascularization (27-29), which generate a highertemperature heat source. Unlike imaging techniques such as X-ray, ultrasonography, MRI, and other structural imaging tools that primarily provide information on the anatomical structures, infrared imaging provides functional information that is not easily measured by other methods. Thus, correct use of DITI (Figure 3) images requires in-depth physiological knowledge for effective interpretation. It has been developed to assist physicians in differentiating benign tissue from malignant tissue by characterizing different patterns in the infrared signal emitted by the tissue.

All types of cancer cells deelop angiogenesis which is necessary to sustain the growth of a tumor and an unbalanced metabolic activity that leads to the utilization of a large amount of blood glucose and release of large amounts of lactate into the blood (30). The use of Digital Infrared Imaging is based on the principle that metabolic activity and vascular circulation in both pre-cancerous tissue and the area surrounding a developing cancer is almost always higher than in normal tissue. Because of its extreme sensitivity, these factors have enabled DITI to be a viable technique for visualizing the abnormality. Infrared imaging may find thermal signs suggesting a pre-cancerous state of the breast or the presence an early tumor that is not yet large enough to be detected by physical examination, mammography, or other types of structural imaging. It also provides more dynamic information of the tumor since the tumor can be small in size but be fast growing, making it appear as a hightemperature spot in the DITI. It is also reported that the results of thermography can be correct 8-10 years before mammography can detect a mass in the patient's body (31).

Computerized thermal imaging (CTI) is a new, non-invasive imaging method that is being developed using the principles of traditional thermography but with the addition of digital image reconstruction. Computerized thermal imaging $(\mathrm{CTI})$ is a heat sensing and processing system that uses a thermal sensitive camera to capture a digital image based on heat radiating from the body. After the breast images have been taken, they are analyzed by a computer algorithm and displayed for interpretation by the physician. Breast images are displayed in different colors (red, orange, and yellow) on a computer monitor. Any suspicious area (abnormal heat area) is marked on the digital breast image.

Previous studies reported (15) that a significant number of cancers (30-65\%) can be visualized on prior mammograms on retrospective review. Double reading of mammograms by two radiologists can improve the detection rate of cancer but is expensive and time consuming. The goal of computer aid detection is to improve detection rates in a more efficient and cost-effective manner, as human examination of images is often influenced by various factors such as fatigue, carelessness, andothers. The detection accuracy is also confined by the limitations of the human visual system. In addition to all these factors, a shortage of qualified radiologists also causes an urgent demand for the development of computer technologies. The computerized system collects a series of infrared breast images while the cooled air surrounds the breast. Then the system analyzes and interprets the infrared data using algorithms

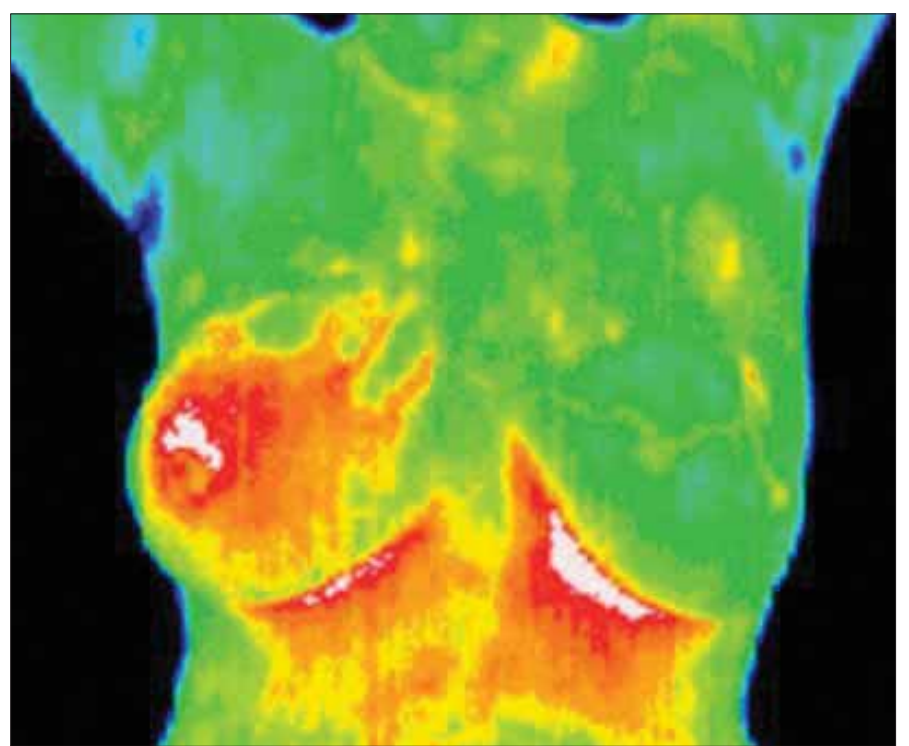

Figure 3. Image of digital infrared thermal imaging (Inflammatory carcinoma of right breast)

that correlate infrared data about the breast being examined to infrared patterns that are associated with either benign or malignant breast tissue. The end result is a numeric score for a given suspicious lesion after the region-of-interest placement. The CTI technology is designed to electronically store the digital breast images and provide the patient with an electronic copy of the images, which may be helpful if she visits another imaging facility. By maintaining close monitoring with infrared imaging, self breast examinations, clinical examinations, mammography, and other tests, a woman has a much better chance of detecting cancer at its earliest stage and preventing invasive tumor growth. In addition, infrared imaging is noninvasive, risk free, patient friendly, and the cost is considerably low. These features, together with its early detection capability, have enabled infrared imaging to be a strong candidate as a complementary diagnostic tool to traditional mammography.

DITI does not use ionizing radiation so this makes it very valuable in the diagnostic procedure of pregnant and younger women. It requires no physical contact, there are no liquids to drink. Difficulties in reading mammograms can occur in women who are on hormone replacement, nursing or have fibrocystic, large, dense, or enhanced breasts. These types of breast differences do not cause difficulties in reading digital infrared scans. It does not require painful levels of breast compression, is not likely to be limited by radiographically dense breast composition, and provides quantitative data that can reduce the interpretive variability associated with mammography.

Infrared imaging data for each subject were acquired during a single imaging session. The subject lay prone on the imaging bed during the procedure with both breasts suspended through openings in the top of the bed. Each breast was imaged individually while the contralateral breast was shielded from the cooled air by a protective gown. Infrared imaging began with a brief period of temperature stasis, after which a stream of cool air was circulated within the refrigeration chamber around the uncovered suspended breast. Multiple infrared images were 
obtained in rapid sequence by the infrared camera both before and during the cooling phase. After the first breast was imaged, the process was repeated for the contralateral breast. The entire session required approximately $15 \mathrm{~min}$, with actual imaging time lasting approximately 3 min per breast (32).

Thermography was approved by the U.S. Food and Drugs Administration (FDA) in 1982 as a supplement to mammography in helping to detect breast cancer. To date, CTI is only available for eligible women who participate in CTI clinical trials. The technology is currently being reviewed but has not been approved by the FDA.

The infrared imaging system has a high negative predictive value which is essential for its clinical use, whereas the positive predictive value does not have as great a clinical utility. Therefore, it is not designed to be a screening tool for identifying or localizing malignancies or to delay biopsy of highly suspicious lesions. It was suggested that the infrared imaging assessment would have adjunctive value to standard clinical practice when both mammography and sonography are commonly used in the decision to recommend biopsy.

Infrared imaging is an economic and safe modality that provides physiologic data about a lesion. The physiologic view provided by infrared imaging complements the anatomic view provided by mammography, with a very high sensitivity and negative predictive value in masses. Infrared imaging holds great promise in the management of breast lesions. It can be used as an adjunct for further evaluating a mammographically apparent breast abnormality when the radiologist has a low-to-moderate suspicion that a malignancy is present. Thus, this dynamic computerized infrared imaging system could be a valuable addition to the physicians' armamentarium of diagnostic tools.

\section{Conclusion}

We reviewed the literature on the accuracy of new technologies proposed for breast cancer screening. Two potential tests were identified Full-field digital mammography (FFDM) and Dijital infrared termal imaging (DITI), for which primary studies met quality and applicability criteria and provided adequate data on test accuracy. These technologies have been assessed in cross-sectional studies of test accuracy where the new test is compared to standard film mammography. As a result, much attention has been devoted to developing improved radiographic techniques for breast cancer screening and evaluation. X-ray mammography is inexpensive and reliable, but the patient is exposed to ionizing radiation and the test is uncomfortable to the patient due to breast compression. If the breasts are dense or have implants, it is very difficult to obtain adequate images. Direct comparision of digital to film mammography revealed that the recall rate, biopsy rate, and specificity of FFDM were almost identical to those of SFM. However, FFDM had higher sensitivity for breast cancer than SFM, particularly among younger women with denser breasts. The area under the curve was significantly greater for FFDM compared with SFM for women under the age of 50 years, women who were not postmenopausal, and women with heterogeneously or extremely dense breasts. On the other hand, SFM may be more suitable for older women with less dense breasts.
Breast ultrasonography is a relatively inexpensive, and effective method with non-ionizing radiation. It can be used in young and/or pregnant women. It is superior to mammography in differentiation of solid/cystic masses and in evaluation of dense fibroglandular breast tissue, which is the most important inherent limitation of mammography in the diagnosis of breast cancer. Although some researchers have reported reasonable results from US breast screening, experts recommend mammography as a primary screening method combined with breast ultrasonography in older women.

DITI, can be used as a tool for breast cancer detection. It is a comfortable, simple and safe method. It can be used also for young women with dense breasts for whom mammography is not very effective and for pregnant women. The evidence is currently insufficient to support the use of any of these new technologies in population screening, but would support further evaluation.

\section{Conflict of interest}

No conflict of interest is declared by authors.

\section{References}

1. Parkin DM, Bray, Ferlay J, Pisani P. Global Cancer Statistics, 2002. CA Cancer J Clin 2005; 55: 74-108.

2. Swan J, Breen N, Coates RJ, Rimer BK, Lee NC. Progress in cancer screening practices in the United States: results from the 2000 National Health Interview Survey. Cancer 2003; 97: 1528-40.

3. Dündar PE, Özmen D, Öztürk B, Haspolat G, Akyldız F, Çoban S, et al. The knowledge and attitudes of breast self-examination and mammography in a group of women in a rural area in western Turkey. BMC Cancer. 2006; 6: 43.

4. Tuncer M. In: Significance of cancer in Turkey, the burden of disease and cancer control policies. Tuncer M, editor. Vol. 74. Cancer Control in Turkey, Ankara, Onur Press, Health Ministry Publication; 2008. pp. 5-9.

5. Statistical analyses of National Breast Cancer Registry Program of Turkish Federation of Breast Societies 2008 Executive summary of the national cancer control programmes: policies and managerial guidelines. Geneva: World Health Organization; 2002.

6. Parkin DM, Bray F, Ferlay J, Pisani P. Global cancer statistics, 2002. CA Cancer J Clin. 2005; 55: 74-108.

7. Ozmen V. Breast cancer in the World and Turkey. J Breast Health. 2008; 4: 6-12.

8. Bland $\mathrm{KI}$, Menck HR, Scott-Conner $\mathrm{CEH}$, Morrow M, Winchester DJ, Winchester DP. The National Cancer Data Base 10-year survey of breast carcinoma treatment at hospitals in the United States. Cancer 2000; 83: 1262-73.

9. Michaelson JS, Silverstein M, WyattJ , Weber G, Moore R, Halpern E, et al. Predicting the survival of patients with breast carcinoma using tumor size. Cancer. Aug 15 2002; 95: 713-23.

10. Olsen O, Gotzsche PC. Cochrane review on screening for breast cancer with mammography. Lancet 2001; 358: 1340-2.

11. ACOG. Practice Bulletin (2003) Breast cancer screening. Int J Gynaecol Obstet 2003; 81: 313-23.

12. Smith RA, Saslow D, Sawyer KA, Burke W, Costanza ME, Evans WP III, et al. American Cancer Society guidelines for breast cancer screening: update 2003. CA Cancer J Clin 2003; 53: 141-69.

13. Humphrey LL, Helfand M, Chan BK, Woolf SH. Breast cancer screening: a summary of the evidence for the U.S. Preventive Services Task Force. Ann Intern Med 2002; 137: 347- 60.

14. Gotzsche PC. Mammographic screening: no reliable supporting evidence? Lancet 2002; 359: 706. 
15. Elmore JG, Armstrong K, Lehman CD, Fletcher SW. Screening for breast cancer. J Am Med Assoc 2005; 293: 1245-56.

16. Fischer U, Hermann KP, Baum F. Digital mammography: current state and future aspects. Eur Radiol 2006; 16: 38-44.

17. Noel A, Thibault F. Digital detectors for mammography: the technical challenges. Eur Radiol 2004; 14: 1990-8.

18. Pisano ED, Yaffe MJ. Digital mammography. Radiology 2005; 234: 353-62.

19. Huda W, Sajewicz AM, Ogden KM, Dance DR. Experimental investigation of the dose and image quality characteristics of a digital mammography imaging system. Med Phys 2003; 30: 442-8.

20. Mahesh M. AAPM/RSNA physics tutorial for residents: digital mammography: an overview. Radiographics 2004; 24: 1747-60.

21. Jackson VP, Reynolds HE, Hawes DR. Sonography of the breast. Semin Ultrasound CT MR. Oct 1996; 17: 460-75.

22. Sickles EA. Breast imaging: from 1965 to the present. Radiology. Apr 2000; 215: 1-16.

23. Weinstein SP, Conant EF, Orel SG, Zuckerman JA, Bellah R., Spectrum of US findings in pediatric and adolescent patients with palpable breast masses. Radiographics. Nov-Dec 2000; 20: 1613-21.

24. Schonberg M.A., Ramanan R.A., McCarthy E.P., MarcantonioE.R. Decision making and counseling around mammography screening for women aged 80 or older. J. Gen. Intern Med.2006; 21: 979-85.
25. Bloomquist AK, Yaffe MJ, Pisano ED, Hendrick RE, Mawdsley GE, Bright S, et al. Quality control for digital mammography in the ACRIN DMIST trial: part I. Med Phys 2006; 33: 719-36.

26. Bick U. Full-field digital mammography. Fortschr Röntgenstr 2000; 172: 957-64.

27. J iang LJ, Ng EY, Yeo AC, Wu S, Pan F, Yau WY. et al. A Perspective on Medical Infrared Imaging. J Med Technol 2005; 29: 257-67.

28. Bagavathiappan S, Saravanan T, Philip J, Jayakumar T, Raj B, Karunanithi $\mathrm{R}$, et al. Infrared thermal imaging for detection of peripheral vascular disorders.J Med Phys. 2009; 34: $43-7$.

29. Stec B, Dobrowolski A, Susek W. Multifrequency microwave thermograph for biomedical applications. IEEE Trans Biomed Eng. 2004; 51: 548-51.

30. Ng EY, Sudarshan NM. Numerical computation as a tool to aid thermographic interpretation. J Med Eng Technol. 2001; 25: 53-60.

31. Ng EY, Ung LN, Ng FC, Sim LS. . Statistical analysis of healthy and malignant breast thermography. Journal of Medical Engineering and Technology 2001; 25: 253-63.

32. Duffy SW, Tabar L, Smith RA. The mammographic screening trials: commentary on the recent work by Olsen and Gotzsche. CA Cancer J Clin 2002; 52: 68-71. 